OPEN ACCESS

Edited by:

Nihal Ahmad,

University of Wisconsin-Madison,

United States

Reviewed by:

loana Cosgarea,

Newcastle University, United Kingdom Yang Wang,

Peking University First Hospital, China

*Correspondence:

Reinhard Dummer reinhard.dummer@usz.ch

Specialty section:

This article was submitted to

Skin Cancer,

a section of the journal

Frontiers in Oncology

Received: 12 March 2020

Accepted: 09 June 2020

Published: 07 August 2020

Citation:

Lang CCV, Ramelyte E and Dummer R (2020) Innovative Therapeutic Approaches in Primary Cutaneous B

Cell Lymphoma.

Front. Oncol. 10:1163.

doi: 10.3389/fonc.2020.01163

\section{Innovative Therapeutic Approaches in Primary Cutaneous B Cell Lymphoma}

\author{
Claudia C. V. Lang ${ }^{1,2}$, Egle Ramelyte ${ }^{1,2}$ and Reinhard Dummer ${ }^{1,2 *}$ \\ ${ }^{1}$ Department of Dermatology, University Hospital Zurich, Zurich, Switzerland, ${ }^{2}$ Medical Faculty, University of Zurich, Zurich, \\ Switzerland
}

Background: Primary cutaneous B-cell lymphomas ( $\mathrm{pCBCL}$ ) include an infrequent group of non-Hodgkin lymphomas that are limited to skin sites at the time of diagnosis. They comprise roughly 20-25\% of all cutaneous lymphomas and are subdivided into primary cutaneous marginal zone lymphoma (PCMZL), primary cutaneous follicle center lymphoma (PCFCL), and primary cutaneous diffuse large cell B cell lymphoma, leg type (PCDLCBCL, LT). The first two show a rather indolent course while PCDLCBCL, LT carries a worse prognosis. Intravascular large cell B-cell lymphoma is the most infrequent subtype, and its therapy is not covered in this review.

Topical Therapy: For solitary, single-site PCMZL and PCFCL, several topical treatment options exist. They include, but are not limited to, excision, radiotherapy, and intralesional therapies, discussed in this review. However, in selected cases, even "watchful waiting" is reasonable.

Systemic Therapy: Indolent types of $\mathrm{PCBCL}$ rarely require systemic treatment. However, in extended cases and more importantly DLCBCL, LT, systemic treatment is the first choice. Monoclonal anti-CD20-antibody rituximab is often used as monotherapy in PCMZL and PCFCL or combined with chemotherapy in PCDLBCL, LT. Newer options are monoclonal anti-CD40 antibody dacetuzumab, anti-PD-1 and anti-PD-L1 checkpoint inhibitors, and Bruton tyrosine kinase inhibitors.

Conclusion: Indolent $\mathrm{pCBCL}$ are treated with a risk-adapted strategy using intralesional steroids, RT, and interferon- $\alpha$ as first-line treatments. Relapsing cases may profit from rituximab. In aggressive PCDLCBCL, $L T$, rituximab with polychemotherapy is recommended. Innovative therapies include intralesional oncolytic virotherapy, systemic monoclonal antibodies, and small molecules.

Keywords: $\mathrm{CBCL}$, radiotherapy, T-VEC, dacetuzumab, bruton thyrosine kinase, intralesional interferon alpha

\section{INTRODUCTION}

Primary cutaneous lymphomas are a group of extranodal non-Hodgkin lymphomas, which present in the skin without signs of systemic involvement at the time of diagnosis (1). The incidence in Western countries is 1 in 100,000, 20-25\% of which are primary cutaneous B-cell lymphomas (pCBCL) (2). Most common pCBCL are primary cutaneous marginal zone lymphoma (PCMZL), primary cutaneous follicle center lymphoma (PCFCL), and primary cutaneous diffuse large B-cell 
lymphoma, leg type (PCDLBCL, LT). Even though all three entities arise from B-cells, they show different clinical courses and carry different prognoses. PCMZL and PCFCL are considered low-grade lymphomas. Despite the high rate of cutaneous relapses, they respond well to therapies and usually have an excellent prognosis. PCDLBCL, LT is a high-grade lymphoma, which carries a worse prognosis and usually requires aggressive treatment approaches.

For localized low-grade lymphomas, skin-directed therapies with surgery, intralesional corticosteroids or interferon- $\alpha$, and radiotherapy are vivid treatment options $(3,4)$. Despite high initial response rates, relapses are common. In generalized, relapsing, and advanced cases, systemic chemotherapy or immunotherapy is required. In aggressive cases, such as PCDLBCL, LT, a combination chemotherapy with monoclonal antibodies, i.e., R-CHOP (rituximab, cyclophosphamide, doxorubicin, vincristine, prednisone) is the most common implemented therapy. However, over $50 \%$ of patients fail to respond to therapy or, more commonly, develop a relapse after initial response $(5,6)$. Moreover, aggressive chemotherapy can seldom be administered in elderly frail patients. These limitations along with the observed similar response pattern to skin-directed and systemic therapies support the need of new therapeutic approaches for patients with widespread, refractory, and relapsing diseases.

\section{TOPICAL THERAPIES}

\section{Excision}

Surgical excision is among the recommended first-line therapies for solitary pCBCL lesions (4). Senff et al. reported on 75 PCMZL patients treated with excisions. In this cohort, all but one patient achieved complete response; however, $43 \%$ of patients developed a relapse. As the site of relapse (local recurrences vs. relapse on other sites) was not reported, the actual cure rate remains unclear; also a clear definition of safety margins in the literature is missing (6).

\section{Radiotherapy}

Along with the excision, radiotherapy (RT) is recommended as a first-line therapy for solitary lesions. It is also a good treatment option for systemic therapy-resistant pCBCL lesions. Different types of RT can be implemented, including electrons and low-energy X-rays. If treated with electrons, the required energy recommendation ranges between 6 and $9 \mathrm{MeV}$ for depth coverage. Low-energy X-rays $(\sim 100 \mathrm{kV})$ may be used alternatively. The recommended total dose range varies between 20 and 36 Gy for PCMZL and PCFCL (NCCN recommends 24 to $30 \mathrm{~Gy}$; EORTC/ISCL recommend 20 to $36 \mathrm{~Gy}$ for PCMZL and $>30$ Gy for PCFCL).

Recommendations for safety margins with RT also vary in the literature and ranges between 0.5 and $5.0 \mathrm{~cm}$. The EORTC/ISCL and ILROG recommend a margin of 1.0 to $1.5 \mathrm{~cm}$ for PCMZL and PCFCL (6).

Due to the high relapse rate, even solitary and localized PCDLBCL, LT lesions should be treated with first-line R-CHOP followed by localized RT with safety margins of $1-2 \mathrm{~cm}$. For electrons, an energy of 6-9 MeV can be used, and a dose of 36$40 \mathrm{~Gy}$ is recommended. In cases without systemic pretreatment, a full dose of 40 Gy should be applied (7).

In a palliative regimen for pCBCL, low-dose RT can be applied with a total dose of $4 \mathrm{~Gy}$ given in two fractions within 2-4 days. Neelis et al. showed that, with this regimen, complete response at $4-6$ weeks could be achieved in $75 \%$ of the 18 treated pCBCL patients with 44 different lesions in total (8).

\section{Antibiotics}

Even though the literature around the role of B. burgdorferi in PCMZL is not conclusive, PCR examination is still positioned in routine workups, and the association should be further investigated (4). In B. burgdorferi infection-associated PCMZL, antibiotic therapy should be attempted before more aggressive therapies are used. However, the literature regarding indication, efficacy, and antibiotic treatment course is not univocal. Senff et al. report in their review about 14 patients, of which $43 \%$ achieved complete remission after various antibiotic regimens (cephalosporins, e.g. cefuroxime $500 \mathrm{mg}$ bid, and tetracyclines, e.g. doxycycline $100 \mathrm{mg}$ bid, both usually given over 3 weeks). In a small cohort of eight patients, they specify intravenous treatment with cephalosporins seems to be superior to oral treatment with high-dose tetracyclines (6).

\section{Intralesional Regimens}

For solitary PCMZL and PFBCL lesions, intralesional regimens are simple, cost-effective, and efficient treatment options. Intralesional steroids, e.g., triamcinolone diluted with lidocaine, lead to lesion size reduction within 2-3 applications with a 3 - to 4 -weeks interval. There are a few side effects except for the risk of skin atrophy (9). Only limited data on intralesional treatment with interferon- $\alpha$ (IFN- $\alpha)$ is available. One study reported successful use of intralesional IFN- $\alpha$ in eight PCMZL patients. The dosing of 3 million IU three times per week led to complete remission after a median of 8 weeks (10). The intralesional administration of rituximab was only administered in nine patients with $5-30 \mathrm{mg}$ once or three times a week, of which eight (89\%) reached complete remission with a $62 \%$ relapse rate (6).

\section{Modified Viruses}

Genetically modified viruses are an upcoming intralesional treatment option. For pCBCL, there are two different virus types available: non-replicating viruses used as vectors (adenovirus interferon- $\gamma$ ) and replicating viruses (Talimogene laherparepvec). Dreno et al. performed a phase II open-label multicenter study with repeated intralesional administration of adenovirus interferon- $\gamma$ (TG1042). TG1042 is an adenovirus five expressing the cDNA of the human IFN- $\gamma$ gene. The virus was chosen due to a short half-life and significant side effects upon systemic treatment with cytokine IFN- $\gamma$. Thirteen patients were enrolled, and 11 (85\%) showed an objective response with a median progression-free survival of 23.5 months. The intralesional administration of TG1042 showed most commonly minor to moderate flu-like symptoms (11). 
An ongoing phase I clinical trial is exploring intralesional talimogene laherparepvec (T-VEC) in non-melanoma skin cancer, including cutaneous lymphomas (NCT03458117). TVEC is a genetically engineered Herpes simplex 1 virus, which is modified to replicate in tumor cells and stimulate adaptive immunity. In metastatic melanoma, it caused responses not only in injected, but also in non-injected metastases $(12,13)$. The same treatment regimen is used in the clinical trial with initial injections of $10^{6} \mathrm{PFU} / \mathrm{ml}$ followed by $10^{8} \mathrm{PFU} / \mathrm{ml}$ every 2 weeks.

\section{Topical Imiquimod}

Topical imiquimod can be used as an immunomodulator via activation of the transcription factor NF- $\mathrm{B}$ via the Toll-like receptor 7 (TLR7) and Toll-like receptor 8 (TLR8) signaling pathways. This activation leads to production of proinflammatory mediators, such as IFN- $\alpha$, IFN- $\gamma$, interleukin 12 , and tumor necrosis factor- $\alpha$, which activate antigen-presenting cells and induce T-helper 1 (Th1) antitumoral cellular immune response (14). There are several case reports and a few small studies available showing topical imiquimod as an option in indolent pCBCL; however, the results are more promising for primary cutaneous $\mathrm{T}$ cell lymphomas (pCTCL) than pCBCL. The treatment frequency ranged from once daily to once weekly applications and was generally well-tolerated; time to response was reached after 2 weeks on average. Severe reactions mostly developed in patients on an intensive regimen and could be avoided with less frequent applications (15).

\section{Photodynamic Therapy}

Photodynamic therapy (PDT) is the combination of a photosensitizer, e.g., 5-aminolevulinic acid (5-ALA, or its methyl ester), light, and oxygen. The photosensitizer is applied to the treatment area, accumulates in abnormal skin tissue, and converts it into protoporphyrin IX. In the presence of light (visible to infrared spectrum), it leads to a photochemical and phototoxic reaction using free oxygen radicals, which leads to cell death. The common use for PDT is mainly for treatment of non-melanoma skin cancer and field cancerization (16). There are only a few case reports and studies for the use in primary cutaneous lymphoma, mainly for pCTCL (15). Mori et al. treated three patients with single early pCBCL lesions using 5-ALA and red light within a standard dose setting for basal cell carcinoma. All three patients reached complete remission after a single session with a follow- up period between 8 and 17 months (17).

\section{SYSTEMIC THERAPIES}

\section{Monoclonal Antibodies}

\section{Rituximab and Versions of It}

CD20 is a B cell differentiation antigen, expressed as a surface molecule on all B lineage cells. Rituximab is the first chimeric monoclonal antibody $(\mathrm{mAb})$ that showed positive results in systemic B cell malignancies and also cutaneous Bcell lymphomas (18). It binds to CD20 on malignant and benign B-cells and elicits its effect through cell apoptosis, antibodydependent cellular cytotoxicity (ADCC), and complementmediated cytotoxicity (19). Used as monotherapy in a small subset of pCBCL patients, rituximab resulted in an overall response rate (ORR) of $89 \%$. However, within a median 52months of follow up, $81 \%$ patients developed a relapse at a median time to relapse of 25 months (18). However, no larger clinical trials in pCBCL have been conducted so far (20).

In advanced pCBCL and nearly all DLCBCL, LT cases, a combination of immunochemotherapy with R-CHOP is the firstline treatment. An observed complete response to CHOP-like chemotherapy in patients with DLCBCL, LT reaches $81 \%$ with a subsequent relapse in $56 \%$ cases. These results are reported from 32 patients treated in eight separate clinical trials (6) as, even though commonly implemented, only limited cases of R-CHOP in $\mathrm{PCBCL}$ are reported.

In refractory cases, rituximab can also be applied in combination with other systemic therapies. A patient with DLCBCL, LT, who relapsed after radiotherapy and R-CGOP (rituximab, cyclophosphamide, gemcitabine, vincristine, prednisone), was treated with a combination of rituximab, lenalidomide antiPD-1 antibody pembrolizumab (21). The patient developed a complete response, which was still ongoing at 7 months after the initiation of therapy. Given this complex immune-modulating treatment, the patient developed a transient neutropenia and pneumonia, which responded to antibiotic therapy.

A new generation of higher affinity, lower immunogenicity, and increased efficacy anti-CD20 antibodies are being investigated. Among those are also antiCD20 mAbs with radioactive molecules. This approach with antiCD20-Mab IgG-radioconjugates Y-ibrutumab (Ibritumomab tiuxetan) and I-tositumomab (Iodine I 131 Tositumomab) is an already FDA approved treatment for nodal B-cell lymphoma $(22,23)$ and might be applied in advanced pCBCL cases.

\section{Other Monoclonal Antibodies}

CD40 is a member of the TNF-receptor superfamily and is expressed on healthy B-cells as well as some B-cell neoplasms, such as chronic lymphocytic leukemia, non-Hodgkin lymphoma, and multiple myeloma. It functions as a co-stimulatory molecule upon the interaction with CD40-ligand (CD40L) and CD154 on T-cells $(24,25)$. It plays a critical role in stimulating antigen presentation, priming of helper- and cytotoxic T-cells and various inflammatory reactions. In cancer, it is involved in the regulation of cancer-cell survival and the presentation of tumor-associated antigens (24).

Dacetuzumab (SNG-40) is a humanized IgG1 anti-CD40Mab. In vitro, dacetuzumab acts like a partial agonist and does not prevent CD40/CD40L interaction. It also has little effect on normal B-cells, but kills malignant B-cells through ADCC and antibody-dependent phagocytosis (26). In a phase II clinical trial with dacetuzumab monotherapy in relapsed systemic DLCBCL patients, it demonstrated a modest overall response rate of $9 \%$ and had relatively a high rate of grade 3-4 lymphopenia (41\%). However, it achieved disease control in $37 \%$ of patients, which suggests this medication may be adapted in different dosing or in combination with other therapeutics and may have a role in treatment of B-cell malignancies, including pCBCL (27). 
The presence of myeloid-derived suppressor cells (MDSC) in the tumor microenvironment correlates to worse prognosis in solid tumors. In DLCBCL, LT, CD33-positive MDSC are present. This could explain the poor prognosis but also provides an opportunity for blockage with humanized anti-CD33 Mab, which has already shown positive results in acute myeloid leukemia (28). No clinical trials that include PCBCL patients are ongoing yet.

\section{Bispecific T-Cell Engaging (BiTE) Antibodies}

A bispecific T-cell engaging (BiTE) antibody is a protein, which can bind two different antigens simultaneously. In Bcell malignancies, an antiCD19/CD3 mAb-blinatumomab-is being explored. CD19 is a differentiation antigen, expressed on the B-cells during all differentiation phases except for plasma cells. Blinatumomab is a $55-\mathrm{kDa}$ fusion protein that simultaneously links CD3 and CD19. A transient cytolytic synapsis between a cytotoxic T-cell and a CD19-positive cell is formed, which results in the lysis of the CD19 cell (29, 30). Therapy with blinatumomab is currently focused on Bprecursor acute lymphoblastic leukemia, but promising results were also obtained in relapsed or refractory DLCBCL, LT (31). However, it might not be suitable for advanced PCMZL cases as high numbers of plasma cells might be observed in some PCMZL cases. However, another BiTe, XmAb13676, which binds $\mathrm{CD} 20 / \mathrm{CD} 3$, is currently being investigated in a phase I clinical trial in patients with CD20-expressing hematologic malignancies (NCT02924402).

\section{Checkpoint Inhibitors}

Immunotherapies are playing an increasing role in modern cancer therapy. Immune response and T-cell activation is a highly regulated process. Checkpoints, such as programmed death 1 (PD-1) are expressed on the surface of T-cells and facilitate sending inhibitory feedback signals to control the cytotoxic T-cell activity and autoimmunity. In solid tumors, PD1 and PD-ligand 1 (PD-L1) inhibitors show impressive responses (32) and significantly prolong overall survival compared to previously used therapies. Checkpoint inhibitors are also used in lymphocytic malignancies. In Hodgkin's lymphoma, increased PD-L1 expression on the malignant Hodgkin Reed Sternberg cells results from genetic amplification at chromosome 9p24.1 (33). In a group of treatment naïve and pretreated patients, antiPD-1 monotherapy resulted in ORR of $69 \%$ with CR in $16 \%$ of patients (34).

In $\mathrm{pCBCL}$, gene alterations, which result in PD-L1/PD-L2 upregulation were identified in DLCBCL, LT, but not in lowgrade lymphomas (35). However, the biological function of PD1/PD-L1 expression is less clear in lymphocytic malignancies. In PCTCL, where the meaning of PD-1/PD-L1 expression is also less clear, antiPD1 antibody pembrolizumab was tested in a clinical trial and resulted in $38 \%$ objective response rate in heavily pretreated cutaneous PCTCL patients (36).

Interestingly, in contrast to solid tumors, anti-PD-1 efficacy in PCTCL did not correlate with the expression of PD-L1, total mutational burden, or an interferon-gamma gene expression signature (36), which suggest that indolent pCBCLs may also respond without having the upregulated PD-1/PD-L1.

\section{Small Molecules BTK Inhibitors}

Bruton Tyrosine Kinase (BTK) is a cytoplasmic, non-receptor tyrosine kinase, predominantly expressed in B-lymphocytes, myeloid cells, and platelets. The BTK pathway is involved in Bcell receptor (BCR) signaling and plays a role in cell proliferation and survival. It is activated in multiple malignancies, including chronic lymphocytic leukemia, acute lymphoblastic leukemia, mantle cell lymphoma, diffuse large B-cell lymphoma, and others (37-41).

Ibrutinib is a first-in-class irreversible BTK inhibitor, which binds to the kinase by a covalent bond and inhibits continuous signaling, thus inhibiting cell proliferation. It is approved for lymphocytic malignancies with activated BKT signaling, including CLL (42), mantle cell lymphoma (43), and marginal zone lymphoma (44). A clinical trial explored the efficacy of ibrutinib in relapsed and/or refractory DLCBCL patients. The ORR was 25\% (20/80) with CR in eight patients and partial response (PR) in 12 patients (45). In DLCBCL, LT, an 80-yearold patient was reported to achieve a complete clearance of skin involvement after ibrutinib treatment (46). However, the patient developed nodal disease 2 months after treatment start.

As seen in other B-cell malignancies, acquired resistance to $\mathrm{BTK}$ inhibitors is often caused by mutant $\mathrm{BTK}^{\mathrm{C} 481 \mathrm{~S}}$. In $\mathrm{BTK} \mathrm{K}^{\mathrm{C} 481 \mathrm{~S}}$ the covalent bond between BTK and the inhibitor is disrupted, which results in reduced drug efficacy. XMU-MP-3 is a lowmolecular-weight, non-covalent BTK inhibitor, which has been shown to bind and inhibit both BTK and $\mathrm{BTK}{ }^{\mathrm{C} 481 \mathrm{~S}}$ in vitro and in vivo (47). So far, no clinical trials have been initiated.

\section{Lenalidomide}

Lenalidomide is an immunomodulatory drug used in multiple myeloma. Lenalidomide enhances the activity of cytotoxic T cells and natural killer cells. The upregulation of tumor-suppressor genes results in inhibition of cell signaling engaging NK-kB and IFN- $\beta$ signaling, which elicits antiproliferative and antiangiogenic effects $(40,48)$. Lenalidomide was explored as monotherapy in DLCBCL, LT, where it achieved a 6-months overall response rate in $26.3 \%$ of patients. Four out of 19 patients have achieved CR, and eight (42\%) have achieved disease control (49). As mentioned above, it shows promising results in combination with other treatments, such as immunotherapy.

\section{Venetoclax}

BCL-2 is a protein that inhibits apoptosis by preventing the release of cytochrome $\mathrm{c}$ from the mitochondrial intermembrane space. The $t_{(14,18)(\mathrm{q} 32.3 ; \mathrm{q} 21.3)}$ chromosomal translocation, which is common in systemic follicle center lymphoma, results in constitutive expression of BCL-2 and increased resistance to apoptosis (50). BCL-2 inhibitor Venteloclax (ABT-199) binds to BCL-2 protein and causes events, which activate BAX and BAK and subsequently induce apoptosis $(51,52)$. Venetoclax shows remarkable clinical activity in chronic lymphocytic leukemia; however, despite high-level 
expression of BCL-2 in systemic DLBCL, responses in this malignancy are seldom (53). It is possible, that co-expression of other anti-apoptotic BCL-2 family proteins may limit activity, and addition of other agents must be needed in DLCBCL Venetoclax has not been explored in pCBCL, but similar approaches with the need of combination therapy may be required.

\section{CONCLUSION}

Localized PCBCL (PCMZL, PCFCL) shows high 5-yeara diseasespecific survival rates ( 99 vs. $95 \%$, respectively); hence, an active "wait and see" approach is often applicable. Skin-directed treatment regimens are first-line options for PCMZL and PCFCL, but all patients should be monitored for disease relapse independent of the applied treatment.

When it comes to PCDLBCL, LT, a quick and effective treatment start is crucial. First-line treatment is a systemic R-CHOP regimen with adjuvant radiotherapy. If polychemotherapy is contraindicated, disease control can be achieved with rituximab monotherapy in combination with radiotherapy for special cases. Radiotherapy alone only plays a role in palliative care regimens.

Systemic treatments almost exclusively play a role in PCDLBCL, LT, and systemic (extracutaneous) lymphoma. In resistant/relapsing cases or in patients with extensive cutaneous

\section{REFERENCES}

1. Willemze R, Cerroni L, Kempf W, Berti E, Facchetti F, Swerdlow SH, et al. The 2018 update of the WHO-EORTC classification for primary cutaneous lymphomas. Blood. (2019) 133:1703-14. doi: 10.1182/blood-2018-11-881268

2. Nicolay JP, Wobser M. Cutaneous B-cell lymphomas - pathogenesis, diagnostic workup, and therapy. J Dtsch Dermatol Ges. (2016) 14:120724. doi: $10.1111 /$ ddg. 13164

3. Gilson D, Whittaker SJ, Child FJ, Scarisbrick JJ, Illidge TM, Parry EJ, et al. British association of dermatologists and UK Cutaneous Lymphoma group guidelines for the management of primary cutaneous lymphomas. $\mathrm{Br} J$ Dermatol. (2019) 180:496-526. doi: 10.1111/bjd.17240

4. Willemze R, Hodak E, Zinzani PL, Specht L, Ladetto M, Committee EG. Primary cutaneous lymphomas: ESMO clinical practice guidelines for diagnosis, treatment and follow-up. Ann Oncol. (2018) 29 (Suppl 4):iv3040. doi: 10.1093/annonc/mdy133

5. Grange F, Joly P, Barbe C, Bagot M, Dalle S, Ingen-Housz-Oro S, et al. Improvement of survival in patients with primary cutaneous diffuse large B-cell lymphoma, leg type, in France. JAMA Dermatol. (2014) 150:53541. doi: 10.1001/jamadermatol.2013.7452

6. Senff NJ, Noordijk EM, Kim YH, Bagot M, Berti E, Cerroni L, et al. European organization for research and treatment of cancer and international society for cutaneous lymphoma consensus recommendations for the management of cutaneous B-cell lymphomas. Blood. (2008) 112:16009. doi: 10.1182/blood-2008-04-152850

7. Specht L, Dabaja B, Illidge T, Wilson LD, Hoppe RT. Modern radiation therapy for primary cutaneous lymphomas: field and dose guidelines from the international lymphoma radiation oncology group. Int J Rad Oncol Biol Phys. (2015) 92:32-9. doi: 10.1016/j.ijrobp.2015.01.008

8. Neelis KJ, Schimmel EC, Vermeer MH, Senff NJ, Willemze R, Noordijk EM. Low-dose palliative radiotherapy for cutaneous B- and T-cell lymphomas. Int J Rad Oncol Biol Phys. (2009) 74:154-8. doi: 10.1016/j.ijrobp.2008.06.1918

9. Perry A, Vincent BJ, Parker SR. Intralesional corticosteroid therapy for primary cutaneous B-cell lymphoma. $\mathrm{Br} J$ disease, systemic therapy can be considered although clinical data is sparse. A combination of systemic therapy with topical regimens can be applied for skin manifestations, mostly localized RT.

For topical regimens, there is a new approach with the intralesional application of T-VEC, currently investigated in a phase I trial. Otherwise, there are known, reliable treatments with interferon- $\alpha$ or rituximab. Overall, more randomized trials are needed to investigate treatment responses.

The field of systemic treatment is getting more interesting with a growing number of monoclonal antibodies, checkpoint inhibitors (PD1), Bruton kinase inhibitors and other small molecules. Although most of these agents are not registered for pCBCL yet and are only available in off-label or compassionate use settings. The active use of those agents implies a careful choice of patients, which should be made in a multi-interdisciplinary setting of a certified tumor board.

It is challenging to interest pharma companies to invest in trials for these rare indications. Therefore, high-impact numbers are difficult to reach, and data on new and innovative treatments are limited.

\section{AUTHOR CONTRIBUTIONS}

All authors listed have made a substantial, direct and intellectual contribution to the work, and approved it for publication.

\section{Dermatol. (2010) 163:223-5. doi: $10.1111 / \mathrm{j} .1365-2133.2010 .09$ 798.x}

10. Cozzio A, Kempf W, Schmid-Meyer R, Gilliet M, Michaelis S, Scharer $\mathrm{L}$, et al. Intra-lesional low-dose interferon alpha2a therapy for primary cutaneous marginal zone B-cell lymphoma. Leuk Lymphoma. (2006) 47:8659. doi: $10.1080 / 10428190500399698$

11. Dreno B, Urosevic-Maiwald M, Kim Y, Guitart J, Duvic M, Dereure O, et al. TG1042 (Adenovirus-interferon-gamma) in primary cutaneous B-cell lymphomas: a phase II clinical trial. PLoS ONE. (2014) 9:e83670. doi: 10.1371/journal.pone.0083670

12. Andtbacka RH, Kaufman HL, Collichio F, Amatruda T, Senzer N, Chesney J, et al. Talimogene laherparepvec improves durable response rate in patients with advanced melanoma. J Clin Oncol. (2015) 33:27808. doi: $10.1200 /$ JCO.2014.58.3377

13. Fukuhara $\mathrm{H}$, Ino $\mathrm{Y}$, Todo T. Oncolytic virus therapy: a new era of cancer treatment at dawn. Cancer Sci. (2016) 107:1373-9. doi: 10.1111/cas.13027

14. Hengge UR, Benninghoff B, Ruzicka T, Goos M. Topical immunomodulatorsprogress towards treating inflammation, infection, and cancer. Lancet Infect Dis. (2001) 1:189-98. doi: 10.1016/S1473-3099(01)00095-0

15. Farkas A, Kemeny L, French LE, Dummer R. New and experimental skindirected therapies for cutaneous lymphomas. Skin Pharmacol Physiol. (2009) 22:322-34. doi: 10.1159/000241302

16. Morton CA, Szeimies RM, Sidoroff A, Braathen LR. European guidelines for topical photodynamic therapy part 2: emerging indications-field cancerization, photorejuvenation and inflammatory/infective dermatoses. $J$ Eur Acad Dermatol Venereol. (2013) 27:672-9. doi: 10.1111/jdv.12026

17. Mori M, Campolmi P, Mavilia L, Rossi R, Cappugi P, Pimpinelli N. Topical photodynamic therapy for primary cutaneous B-cell lymphoma: a pilot study. J Am Acad Dermatol. (2006) 54:524-6. doi: 10.1016/j.jaad.2005. 10.016

18. Brandenburg A, Humme D, Terhorst D, Gellrich S, Sterry W, Beyer M. Long-term outcome of intravenous therapy with rituximab in patients with primary cutaneous B-cell lymphomas. Br J Dermatol. (2013) 169:112632. doi: 10.1111/bjd.12484 
19. Weiner GJ. Rituximab: mechanism of action. Semin Hematol. (2010) 47:11523. doi: 10.1053/j.seminhematol.2010.01.011

20. Heinzerling LM, Urbanek M, Funk JO, Peker S, Bleck O, Neuber $\mathrm{K}$, et al. Reduction of tumor burden and stabilization of disease by systemic therapy with anti-CD20 antibody (rituximab) in patients with primary cutaneous B-cell lymphoma. Cancer. (2000) 89:183544. doi: 10.1002/1097-0142(20001015)89:8<1835::AID-CNCR26>3.0.CO;2-H

21. Di Raimondo C, Abdulla FR, Zain J, Querfeld C, Rosen ST. Rituximab, lenalidomide and pembrolizumab in refractory primary cutaneous diffuse large B-cell lymphoma, leg type. Br J Haematol. (2019) 187:e79-82. doi: 10.1111/bjh.16211

22. Product Approval Information - Licensing Action Tositumomab. Available online at: https://www.accessdata.fda.gov/drugsatfda_docs/appletter/2003/ tosicor062703L.htm (accessed Feburary 10, 2020).

23. FDA Approval Zevalin (Ibritumomab Tiuxetan). Available online at: https://www.accessdata.fda.gov/drugsatfda_docs/nda/2002/125019_ 0000_ZevalinTOC.cfm

24. Law CL, Grewal IS. Therapeutic interventions targeting CD40L (CD154) and CD40: the opportunities and challenges. Adv Exp Med Biol. (2009) 647:8-36. doi: 10.1007/978-0-387-89520-8_2

25. Tong AW, Stone MJ. Prospects for CD40-directed experimental therapy of human cancer. Cancer Gene Ther. (2003) 10:1-13. doi: 10.1038/sj.cgt.7700527

26. Law CL, Gordon KA, Collier J, Klussman K, McEarchern JA, Cerveny CG, et al. Preclinical antilymphoma activity of a humanized anti-CD40 monoclonal antibody, SGN-40. Cancer Res. (2005) 65:8331-8. doi: 10.1158/0008-5472.CAN-05-0095

27. de Vos S, Forero-Torres A, Ansell SM, Kahl B, Cheson BD, Bartlett NL, et al. A phase II study of dacetuzumab (SGN-40) in patients with relapsed diffuse large B-cell lymphoma (DLBCL) and correlative analyses of patient-specific factors. J Hematol Oncol. (2014) 7:44. doi: 10.1186/1756-872 2-7-44

28. Gbadamosi M, Meshinchi S, Lamba JK. Gemtuzumab ozogamicin for treatment of newly diagnosed CD33-positive acute myeloid leukemia. Future Oncol. (2018) 14:3199-213. doi: 10.2217/fon-2018-0325

29. Nagorsen D, Baeuerle PA. Immunomodulatory therapy of cancer with $\mathrm{T}$ cell-engaging BiTE antibody blinatumomab. Exp Cell Res. (2011) 317:125560. doi: 10.1016/j.yexcr.2011.03.010

30. Nagorsen D, Kufer P, Baeuerle PA, Bargou R. Blinatumomab: a historical perspective. Pharmacol Ther. (2012) 136:33442. doi: 10.1016/j.pharmthera.2012.07.013

31. Yu J, Wang W, Huang H. Efficacy and safety of bispecific Tcell engager (BiTE) antibody blinatumomab for the treatment of relapsed/refractory acute lymphoblastic leukemia and non-Hodgkin's lymphoma: a systemic review and meta-analysis. Hematology. (2019) 24:199-207. doi: 10.1080/16078454.2018.1549802

32. Postow MA, Chesney J, Pavlick AC, Robert C, Grossmann K, McDermott D, et al. Nivolumab and ipilimumab versus ipilimumab in untreated melanoma. N Engl J Med. (2015) 372:2006-17. doi: 10.1056/NEJMoa141 4428

33. Green MR, Monti S, Rodig SJ, Juszczynski P, Currie T, O'Donnell E, et al. Integrative analysis reveals selective 9p24.1 amplification, increased PD-1 ligand expression, and further induction via JAK2 in nodular sclerosing Hodgkin lymphoma and primary mediastinal large B-cell lymphoma. Blood. (2010) 116:3268-77. doi: 10.1182/blood-2010-05-282780

34. Kasamon YL, de Claro RA, Wang Y, Shen YL, Farrell AT, Pazdur R. FDA approval summary: nivolumab for the treatment of relapsed or progressive classical hodgkin lymphoma. Oncologist. (2017) 22:58591. doi: 10.1634/theoncologist.2017-0004

35. Zhou XA, Louissaint A, Jr., Wenzel A, Yang J, Martinez-Escala ME, et al. Genomic analyses identify recurrent alterations in immune evasion genes in diffuse large B-cell lymphoma, leg type. J Invest Dermatol. (2018) 138:236576. doi: 10.1016/j.jid.2018.04.038

36. Khodadoust MS, Rook AH, Porcu P, Foss F, Moskowitz AJ, Shustov A, et al. Pembrolizumab in relapsed and refractory mycosis fungoides and sezary syndrome: a multicenter phase II study. J Clin Oncol. (2020) 38:208. doi: $10.1200 /$ JCO. 19.01056

37. Cinar M, Hamedani F, Mo Z, Cinar B, Amin HM, Alkan S. Bruton tyrosine kinase is commonly overexpressed in mantle cell lymphoma and its attenuation by Ibrutinib induces apoptosis. Leuk Res. (2013) 37:12717. doi: 10.1016/j.leukres.2013.07.028

38. Herman SE, Gordon AL, Hertlein E, Ramanunni A, Zhang X, Jaglowski S, et al. Bruton tyrosine kinase represents a promising therapeutic target for treatment of chronic lymphocytic leukemia and is effectively targeted by PCI- 32765 . Blood. (2011) 117:6287-96. doi: 10.1182/blood-2011-01-328484

39. Uckun FM, Tibbles HE, Vassilev AO. Bruton's tyrosine kinase as a new therapeutic target. Anticancer Agents Med Chem. (2007) 7:62432. doi: $10.2174 / 187152007784111331$

40. Yang Y, Shaffer AL, 3rd, Emre NC, Ceribelli M, Zhang M, Wright G, et al. Exploiting synthetic lethality for the therapy of $\mathrm{ABC}$ diffuse large $\mathrm{B}$ cell lymphoma. Cancer Cell. (2012) 21:723-37. doi: 10.1016/j.ccr.2012.05.024

41. Yang Y, Shi J, Gu Z, Salama ME, Das S, Wendlandt E, et al. Bruton tyrosine kinase is a therapeutic target in stem-like cells from multiple myeloma. Cancer Res. (2015) 75:594-604. doi: 10.1158/0008-5472.CAN-14-2362

42. Byrd JC, Furman RR, Coutre SE, Flinn IW, Burger JA, Blum KA, et al. Targeting BTK with ibrutinib in relapsed chronic lymphocytic leukemia. $N$ Engl J Med. (2013) 369:32-42. doi: 10.1056/NEJMoa1215637

43. Wang ML, Blum KA, Martin P, Goy A, Auer R, Kahl BS, et al. Long-term follow-up of MCL patients treated with singleagent ibrutinib: updated safety and efficacy results. Blood. (2015) 126:739-45. doi: 10.1182/blood-2015-03-635326

44. Noy A, de Vos S, Thieblemont C, Martin P, Flowers CR, Morschhauser F, et al. Targeting Bruton tyrosine kinase with ibrutinib in relapsed/refractory marginal zone lymphoma. Blood. (2017) 129:2224-32. doi: 10.1182/blood-2016-10-747345

45. Winter AM, Landsburg DJ, Mato AR, Isaac K, Hernandez-Ilizaliturri FJ, Reddy N, et al. A multi-institutional outcomes analysis of patients with relapsed or refractory DLBCL treated with ibrutinib. Blood. (2017) 130:16769. doi: 10.1182/blood-2017-05-786988

46. Fox LC, Yannakou CK, Ryland G, Lade S, Dickinson M, Campbell BA, et al. Molecular mechanisms of disease progression in primary cutaneous diffuse large B-cell lymphoma, leg type during ibrutinib therapy. Int J Mol Sci. (2018) 19:1758. doi: 10.3390/ijms19061758

47. Gui F, Jiang J, He Z, Li L, Li Y, Deng Z, et al. A non-covalent inhibitor XMU-MP-3 overrides ibrutinib-resistant Btk(C481S) mutation in B-cell malignancies. Br J Pharmacol. (2019) 176:4491-509. doi: 10.1111/bph.14809

48. Chanan-Khan AA, Cheson BD. Lenalidomide for the treatment of B-cell malignancies. J Clin Oncol. (2008) 26:1544-52. doi: 10.1200/JCO.2007.14.5367

49. Beylot-Barry M, Mermin D, Maillard A, Bouabdallah R, Bonnet N, DuvalModeste $\mathrm{AB}$, et al. A single-arm phase II trial of lenalidomide in relapsing or refractory primary cutaneous large B-cell lymphoma, leg type. J Invest Dermatol. (2018) 138:1982-9. doi: 10.1016/j.jid.2018.03.1516

50. Tsujimoto Y, Ikegaki N, Croce CM. Characterization of the protein product of bcl-2, the gene involved in human follicular lymphoma. Oncogene. (1987) 2:3-7.

51. Del Gaizo Moore V, Brown JR, Certo M, Love TM, Novina CD, Letai A. Chronic lymphocytic leukemia requires BCL2 to sequester prodeath BIM, explaining sensitivity to BCL2 antagonist ABT-737. J Clin Invest. (2007) 117:112-21. doi: 10.1172/JCI28281

52. Khan N, Kahl B. Targeting BCL-2 in Hematologic Malignancies. Target Oncol. (2018) 13:257-67. doi: 10.1007/s11523-018-0560-7

53. Davids MS, Roberts AW, Seymour JF, Pagel JM, Kahl BS, Wierda WG, et al. Phase I first-in-human study of venetoclax in patients with relapsed or refractory non-hodgkin lymphoma. J Clin Oncol. (2017) 35:82633. doi: 10.1200/JCO.2016.70.4320

Conflict of Interest: The authors declare that the research was conducted in the absence of any commercial or financial relationships that could be construed as a potential conflict of interest.

Copyright (๑) 2020 Lang, Ramelyte and Dummer. This is an open-access article distributed under the terms of the Creative Commons Attribution License (CC BY). The use, distribution or reproduction in other forums is permitted, provided the original author(s) and the copyright owner(s) are credited and that the original publication in this journal is cited, in accordance with accepted academic practice. No use, distribution or reproduction is permitted which does not comply with these terms. 